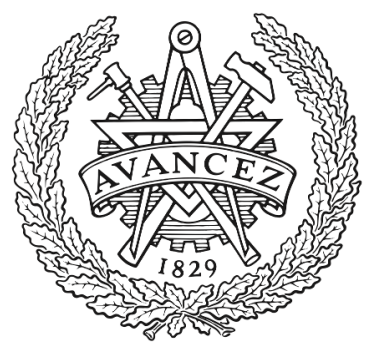

CHALMERS

UNIVERSITY OF TECHNOLOGY

\title{
Digitalisation and quality management: problems and prospects
}

Downloaded from: https://research.chalmers.se, 2023-04-26 09:50 UTC

Citation for the original published paper (version of record):

Elg, M., Birch-Jensen, A., Gremyr, I. et al (2021). Digitalisation and quality management: problems and prospects. Production Planning and Control, 32(12): 990-1003.

http://dx.doi.org/10.1080/09537287.2020.1780509

N.B. When citing this work, cite the original published paper. 


\title{
Digitalisation and quality management: problems and prospects
}

\author{
Mattias Elg ${ }^{\mathrm{a}}$, Andrea Birch-Jensen ${ }^{\mathrm{b}}$, Ida Gremyr ${ }^{\mathrm{a}, \mathrm{b}}$, Jason Martin ${ }^{\mathrm{a}}$ (D) and Ulf Melin ${ }^{\mathrm{a}}$

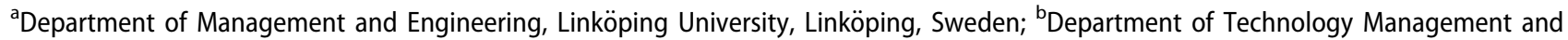 \\ Economics, Chalmers University of Technology, Gothenburg, Sweden
}

ABSTRACT

Digitalisation provides both challenges and opportunities for Quality Management (QM). The purpose of this study is to identify various roles QM practitioners play in digitalisation initiatives to uncover the challenges and potential of QM's digitalisation journey. This issue is addressed through an analytical framework that stresses two dimensions: the exploration and exploitation of digitalised QM processes and value creation, which is performed by the customer or in interactions facilitated by the provider. Through a multiple-case study of four large Swedish organisations, we propose six different challenges and corresponding roles for QM. Further, the study identifies challenges of digitalisation affecting both exploitative and explorative practices throughout an organisation's value creation process. This research contributes to the existing literature with empirical evidence on the challenges induced by digitalisation, an area often discussed but not as often studied empirically.
ARTICLE HISTORY

Received 4 November 2019

Accepted 7 May 2020

\section{KEYWORDS}

Digitalisation; quality management; practices; multiple-case study

\section{Introduction}

Digitalisation is transforming our society in several ways, bringing several new opportunities and challenges for firms operating in this dynamic setting (Tilson, Lyytinen, and Sørensen 2010; Brennen and Kreiss 2016; Esposito De Falco et al. 2017; Lindgren et al. 2019). As this transformation is pervasive, it encompasses changes ranging from individual work tasks to new business models, new forms of relationships, the digitisation of existing practices, and novel technical solutions that provide better customer value. Digitalisation is far from a futuristic prediction but is rather part of today's changing landscape for firms (Ford 2015). Solutions that embed digitalised technologies are found in an increasing range of areas, such as big data analytics, automation, digital interfaces, and connectivity (Brynjolfsson and McAfee 2014), and they have been shown to have both inter- and intra-organisational implications for operations management (Agrifoglio et al. 2017).

It does not come as a surprise that digitalisation has become a strategic priority for organisations but moving forward in this new terrain is seldom a straightforward process (Legner et al. 2017; Zangiacomi et al 2020). Besides affecting processes, organisations, business, and society (Parviainen et al., 2017), the actors in the system will shape and be shaped by digitalisation. One such effect is that current work roles may change (Parviainen et al. 2017; Henriette, Feki, and Boughzala 2016). Hence, organisations need to acknowledge and analyse the need for new knowledge and skills to fill the roles needed in the workplace to make the most out of digitalisation. New individual requirements create a skill gap for those who have extensive business experience but are unfamiliar with emerging digital tools and digitalised processes. There can also be potential tensions when the IT department 'is out of tune with the rest of the organisation' (Kohli and Johnson 2011, 148), as it is a critical department in assisting various organisational functions with the skills needed to execute a digital strategy. An example of such a function that is likely to be affected by digitalisation in terms of new skills needed is quality management (QM).

There are several reasons why digitalisation is shaping the role of QM in organisations. First, many digitalised solutions offer better technical quality with respect to products and services, consequently influencing the direction of QM (Zhou 2013). Second, digital technology has opened up new forms of customer interaction leading to challenges in making use of real-time data from customers (Gölzer and Fritzsche 2017) and finding better ways of providing customer service (Ramaswamy and Ozcan 2018). Third, support for QM's achievements in improving internal processes is now increasingly available through digital solutions (Alič 2018). Fourth, QM activities are - in the same way as digitalisation - not limited to one specific function in an organisation but spread across the whole organisation and its value creation processes (Ponsignon, Kleinhans, and Bressolles 2019). In line with this, it is important to understand the various roles QM may play in digitalisation initiatives. Are there any specific roles that are more easily undertaken, and are there roles that are more problematic? For operations management $(\mathrm{OM})$ in general, this question is also highly important as 
digitalisation potentially influences all aspects of OM (Schiavone and Sprenger 2017).

Even though there are plenty of reports arguing for digital transformation, few empirical studies have been conducted in order to understand how digitalisation affects and challenges contemporary QM practice. A notable example is Ponsignon, Kleinhans, and Bressolles's (2019) work which examines how QM can contribute to a digital transformation, focussing on the professionals' views on the competences available, and needed, to make such a contribution. However, they point out that their research does not depart from a study of actual practices and call for more research investigating actual digitalisation journeys. In response to this, the present study focuses on QM practitioners' actual experiences of digitalisation. The purpose is to identify the various roles QM practitioners play in digitalisation initiatives as a means to uncover the challenges and potential of QM's digitalisation journey. Following this purpose, two research questions are formulated:

RQ1: In what ways are QM practitioners involved in digitalization initiatives?

RQ2: What are the key characteristics of QM practitioners' roles in digitalization initiatives?

The paper is organised as follows. The next section presents a definition of digitalisation followed by a summary of the previous literature on quality and digitalisation. Based on the definition and previous work, this section also provides an analytical framework for studying QM's role in digitalisation. In the subsequent section, we present details from the multiple case study design carried out. We then present the empirical results from the study of four large-scale organisations' digitalisation initiatives. Finally, we highlight six different roles that QM may have in digitalisation and provide concluding remarks.

\section{Theoretical framework}

In this section, we elaborate on QMs role in digitalisation as a basis for the subsequent conceptualisation and empirical work. This is followed by a review of previous literature, focussing on the relationships between QM and digitalisation. Following this review, an analytical framework guiding the analysis of the empirical data is presented.

\section{Digitalisation}

'The digital transformation can be understood as the changes that the digital technology causes or influences in all aspects of human life' (Stolterman and Fors 2004, 689). From an organisation's perspective, digital technologies provide new ways of performing existing practices or processes, as well as completely new practices, processes, and offerings. Taking an existing practice or process and moving it into a digital environment without changing its content or the actors involved is referred to as digitisation (Henriette, Feki, and Boughzala 2016; Parviainen et al. 2017). However, when the business model is changed (Henriette, Feki, and
Boughzala 2016), for example, by changing actors in the value creation process, creating new offerings, or making adaptations to processes, organisations, or ecosystems in order to use digital technologies (cf. Legner et al. 2017; Parviainen et al. 2017), this is referred to digitalisation.

Naturally, a lot of research around digitalisation focuses on the technological innovations per se. However, digitalisation impacts not only digital capabilities but also business models (Ghobakhloo 2018; Zangiacomi et al. 2020), operational processes (Martinez 2019), and customer experiences (Henriette, Feki, and Boughzala 2016). According to Orlikowski and lacono (2000), such an impact is not merely restricted to the internal organisational structures, but also has consequences for the external interconnected environment of the organisation. Parviainen et al. (2017) suggest the following four levels at which digitalisation induces changes:

1. Process level - changes in how work tasks and activities are carried out by implementing new digital tools or digitalising previously manual activities;

2. Organisation level - new ways of providing existing offerings, as well as providing new offerings enabled by digitalisation;

3. Business domain level - changing roles and value chains; and

4. Society level - reshaping types of work, competence, and infrastructure for digitalisation.

\section{Previous research on digitalisation and quality management}

In line with Gastaldi et al. (2018), the literature relating to QM and digitalisation can be organised based on how it addresses (1) antecedents, (2) digitalisation processes, and (3) documented effects in empirical studies.

First, from the literature, several antecedents of digitalisation are identified. At an organisational level, the environment (e.g. competition and technology development) directs the digital development. For instance, one article addresses the newspaper industry's failure to embrace digitalisation, proposing to offer insights into the effects of digitalisation on creative industries, and explains how various industries handle disparate environmental changes (Rothmann and Koch 2014). Moreover, moving from the organisational level to the organisations' output, several studies focus on the influence on digitalisation induced by customers' requirements for individual solutions (e.g. Henriette, Feki, and Boughzala 2016). Another thematic area of antecedents concerns the actor level and certain skills and motivational behaviours that are suitable for adopting digitalised solutions (Billon, Lera-Lopez, and Marco 2010). In line with this, Ponsignon, Kleinhans, and Bressolles (2019) explore the envisioned competences needed for QM to contribute to a digitalisation journey and outline the structural (e.g. methodology and toolbox) and contextual (e.g. collaboration with an IT function) competences needed. The possibility for the actors to exploit the potential of digitalisation is naturally also connected to ICT infrastructure maturity, such as access to 
mobile communications and wireless networks, which is central to digitalisation initiatives (Billon, Lera-Lopez, and Marco 2010; Grover and Ramanlal 2004).

Second, a number of papers focus on digitalisation processes and provide practical cases and examples of how to work with digitalisation (Carlsson 2018; Christiansson, Svidt, and Sørensen 2009; Cocca et al. 2018; Dewa, van der Merwe, and Matope 2018). The starting point for research in this stream can be described as 'what really matters is not just the availability of the ICT infrastructure but the extent and ability to use it in an effective or creative way by individuals and organisations' (Evangelista, Guerrieri, and Meliciani 2014, 805). Studying digitalisation processes beyond the necessary technology and related ICT infrastructure can mainly focus on either external or internal changes. Starting externally, Rothmann and Koch (2014) stress the need to distinguish between the creation of new strategic options and the need for adaptive learning to enable new strategic patterns. Some examples of digitalisation initiatives that create new strategic options and change the eco-system of organisations include: studies of digitalisation initiatives that support empowering patients (Snowdon et al. 2015), removing intermediaries in the supply chain (Parviainen et al. 2017), the need for inter-organisationally compatible ICT structures to facilitate open innovation (Roldán Bravo, Lloréns Montes, and Ruiz Moreno 2017), and managing customised solutions (Zangiacomi et al. 2017). Other studies on digitalisation processes focus on how digitalisation initiatives affect organisations' internal processes. This group of studies includes automated assembly and manufacturing processes (Dewa, van der Merwe, and Matope 2018) and analytics for improving internal processes (Ferrari et al. 2018).

Third, referring to Gastaldi et al. (2018), there is a clear lack of research showing measurable and documented effects of digitalisation and QM in the reviewed literature. To sum up, digitalisation processes have been studied from a wide range of positions. Many papers provide practical cases and examples of how to work with digitalisation (Carlsson, 2018; Christiansson, Svidt, and Sørensen 2009; Cocca et al. 2018; Dewa, van der Merwe, and Matope 2018), however not focussing on the roles QM practitioners' can take or their actual experiences of digitalisation.

\section{Analytical framework}

This section presents the integrated analytical model for analysing the various roles of QM depending on the two dimensions of exploitation - exploration and the three spheres of value creation: the provider sphere, the interaction sphere, and the customer sphere (see Figure 1). The nature of the QM practitioner mandate, and at which organisational level the digitalisation initiatives occur, also form an important component in this analysis. Furthermore, this study particularly focuses on QM as an organisational function, thereby adopting a primarily structural level of analysis. Hence, the analysis of process, organisation and business domain levels is of major interest. However, the macro perspective of the society level (Parviainen et al. 2017) is beyond the scope of this study.

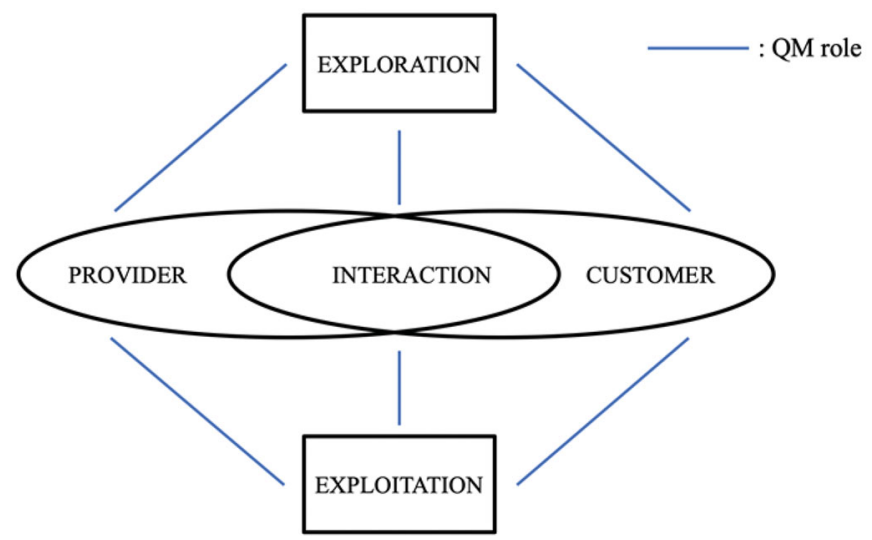

Figure 1. Analytical framework for understanding QM roles in the various forms of value creation in digitalisation initiatives (framework built on Grönroos 2011 and March 1991).

\section{The exploitation-exploration trade-off}

This study examines the role of digitalisation through the concepts of exploitation and exploration. Research on QM has addressed the need for a balance between these two concepts (Benner and Tushman 2003; Gastaldi et al. 2018; O'Reilly and Tushman, 2013; Zhang, Linderman, and Schroeder 2012, 2014). In this paper, exploitation is viewed as practices supporting adaptive change that directly or indirectly enhance existing organisational processes. Exploitative practices refer to adaptation, standardisation, assimilation, routinisation, refinement, efficiency, robustness, execution, and implementation (March 1991). Zhang, Linderman, and Schroeder (2012) describe quality exploitation as practices in identifying existing customers, assessing and understanding customer needs and expectations, increasing process control and reliability, intra-functional problem-solving, and training in existing skills.

Exploration refers to QM practices supporting changes that directly or indirectly develop new organisational processes. Exploratory practices are linked to concepts such as critical evaluation, accommodation, experimentation, risk-taking, variation, flexibility, discovery, and innovation (March 1991). Zhang, Linderman, and Schroeder (2012) describe quality exploration as practices that identify new customers and new customer needs; involve customers in product development; explore new products and processes; and involve dynamic changes of organisation, cross-functional problem-solving, and training in multiple and new skills.

Although exploration and exploitation can be described as conceptual dichotomies (Backström, Fundin, and Johansson 2017), this paper draws on March's (1991) notion that both concepts are essential for managing organisations. The management of exploitative and explorative practices in organisations is referred to as organisational ambidexterity (Duncan 1976). Duncan (1976) argued for organisations to shift their focus over time in what he labelled as sequential ambidexterity. Tushman and O'Reilly (1996) added the notion of simultaneous ambidexterity in that organisations need to combine both exploitative and explorative practices simultaneously in structurally autonomous units. Birkinshaw and Gibson (2004) offer a third way of organising ambidexterity by describing contextual ambidexterity, i.e. allowing 
individual flexibility in the choice between exploitative and explorative practices. At an overall level, O'Reilly and Tushman (2013) argue that organisations need to accommodate both concepts within their operations, although they also argue that not every organisation successfully manages to adopt a deliberate strategy to encompass both.

\section{Balancing the provider-customer focus}

To understand how digitalisation affects $\mathrm{QM}$ in the provision of customer value, service logic (Grönroos 2011), value creation processes (Grönroos 2008, 2011; Ramírez 1999), and value-in-use processes (e.g. Grönroos, 2011) are utilised. Grönroos (2011) puts forth the notion that the customer is the sole creator of value, whilst the organisation that develops and provides a service is a value facilitator. This notion is central to our study, as it informs us about the various forms of value QM can provide.

Based on Grönroos (2011), three spheres of value creation are outlined: (1) the provider sphere, (2) the provider-customer interaction sphere, and (3) the customer sphere. Providers can co-create value with the customer in the interaction sphere. Beyond this sphere, the provider's role is to facilitate value creation through functions such as developing, manufacturing, and delivering resources needed by the customer to create value. Thus, provider activities in the interaction sphere have the potential to impact the customer's value creation and use of the service (Grönroos 2008, 2011). To manage the interaction sphere in a manner that facilitates value creation for the customer, the provider needs to be well-informed about customers' needs and wishes. If the provider fails to manage the interaction sphere sufficiently, the customer may experience a negative impact on value creation. Thus, both value creation and value destruction are possible in the interaction sphere.

To sum up, initiatives related to digitalisation can affect value provision within the provider sphere, the interaction sphere, or the customer sphere. This dimension allows for an analysis of the balance between QM's focus on improving internal processes in the provider sphere and its focus on how the organisation interacts or co-creates value together with customers in the interaction sphere.

\section{Method}

\section{Study design}

The paper seeks to identify the various roles QM practitioners play in digitalisation initiatives. Relying on the study and analysis of the practitioners' experiences and perceptions calls for a qualitative approach (Miles and Huberman 1994). Thus, this paper is based on a qualitative, multiple cross-case study design (Voss, Tsikriktsis, and Frohlich 2002; Yin 2013). The design is motivated by the need to cut across local contexts to enhance analytical generalisability (Miles and Huberman 1994) and the possibilities for drawing analytical conclusions (Yin 2013). Case study designs also provide flexibility for explorative research, where new areas for theorybuilding can be uncovered (Voss, Tsikriktsis, and Frohlich
2002) as in the case of understanding the role of digitalisation for organisations (Zangiacomi et al. 2020; Berlak, Hafner, and Kuppelwieser 2020).

\section{Sampling}

To identify as many digitalisation initiatives as possible and study QM practitioners' experiences with these initiatives, the cases needed two characteristics: (1) experiences with a variety of digitalisation initiatives, and (2) established QM practitioners. First, we decided to strive for variation in sampling (Miles and Huberman 1994) in order to maximise the likelihood of identifying a large range of digitalisation initiatives. Moreover, aiming for variation enhances the possibility of identifying common patterns across diverse case contexts (Patton 2015). Second, to capture experiences of QM practitioners at various organisational levels, the sample of organisations included were therefore large enough to accommodate an established organisational structure for systematised QM work (often in the form of a QM department). The sampling strategy ensured that the case organisations housed established QM functions, including wide use of ISObased management systems, together with formalised organisational structures dedicated to QM work. It also ensured that there were strategic and operational imperatives guiding QM in the organisations.

The case organisation sampling strategy was further directed by an ambition to cover common patterns of $\mathrm{QM}$ practices found within diverse case contexts (i.e. Patton 2015). To accomplish this, three private companies and one organisation in the public sector were approached. The sample of case organisations ensure variation, not only between manufacturing and services production but also in a variety of both business to business, business to consumer and civic services.

To ensure the anonymity of the participating organisations, they will be referred to in this paper as Manufacturing A, Life Science Firm, Government Body, and Manufacturing B. An overview of the organisations' characteristics is presented in Table 1. Manufacturing A produces complex, high-tech products, mainly in a business-to-business market, and sells both products and product-related services. The life science firm is a large production firm within a large group of life science companies, selling products through various dealers. In contrast to the first two organisations, the government body is a pure service provider working with individual citizens on social security issues. Finally, Manufacturing $B$, like Manufacturing $A$, produces complex, high-tech products and associated services, but mainly in a business-to-consumer market.

\section{Data collection}

To obtain relevant data covering the purpose of this study, informants were selected using a 'key informant' sampling strategy (Patton 2015). It is acknowledged that there is a variety of ways to identify key informants, one could focus specific responsibilities in relation to e.g. certified management 
Table 1. Firm characteristics.

\begin{tabular}{|c|c|c|c|c|}
\hline Organisation & Product/service provider & $\mathrm{B} 2 \mathrm{~B} / \mathrm{B} 2 \mathrm{C}$ & Public/Private & Number of employees (rounded to the nearest thousand) \\
\hline Manufacturing $\mathrm{A}$ & Product, product-related services & $\mathrm{B} 2 \mathrm{~B}$ & Private & 100,000 \\
\hline Life Science Firm & Product & $\mathrm{B} 2 \mathrm{~B}$ & Private & 60,000 \\
\hline Government Body & Service & $\mathrm{B} 2 \mathrm{C}$ & Public & 15,000 \\
\hline Manufacturing B & Product, product-related services & $\mathrm{B} 2 \mathrm{C}$ & Private & 40,000 \\
\hline
\end{tabular}

systems like ISO9000 (Goffnett 2020), a certain professional role as e.g. being a Six Sigma Black Belt (Hoerl 2001), or a certain job title as e.g. quality manager (Elg et al. 2011). However, the focus in this paper is not on certain responsibilities, professional roles, or titles, but on the digitalisation initiatives per se in order to encompass an as broad variety of experiences as possible. As the ambition was to cover an array of digitalisation initiatives faced by $\mathrm{QM}$ practitioners working in different roles and practices, the contact person at each organisation was invited to identify potential informants. The instructions were to identify informants in four categories to capture whether the role was centralised or decentralised and strategic or operational. In total, 33 QM practitioners (see Appendix I), with allocated time and designated responsibilities for QM work, spread across the organisations and the four categories, were selected as informants and interviewed.

The data were gathered through thematic, semi-structured interviews (Arksey and Knight 1999), with five interviewers using a predefined interview guide. Two open questions were used to support informants in discussing digitalisation within their practitioner practices: (1) How are you affected by digitalisation and the digitalisation of your organisation regarding work with QM? and (2) What do you perceive to be the biggest obstacles and benefits concerning digitalisation regarding work with $\mathrm{QM}$ ?

Each interview lasted between 45 and $90 \mathrm{~min}$ and was digitally recorded and transcribed verbatim. The original verbatim interview data was then imported into the SQR NVivo software programme. Using NVivo provided the possibility to store, organise, and communicate the data, as well as facilitating coding and subsequent qualitative analysis.

\section{Data analysis}

The analytical work followed an abductive process (Alvesson and Sköldberg 2017) in which an analysis of the empirical data was performed through an iterative combination of inductive and deductive analysis (Patton 2015). The research design governing the data analysis was aimed at identifying key variables, which in this study are digitalisation initiatives and their relationships to the value creation process (Eisenhardt 1989; Voss, Tsikriktsis, and Frohlich 2002). The relationships in focus within the analytical process were how the digitalisation initiatives affect the QM practitioners' work and how these initiatives challenge or re-shape their work practices. The data analysis can be described through the following five main steps:

1. Reading (and re-reading);

2. Reducing data by coding;
3. Clustering of codes (with ordering and categorisation);

4. Comparing, relating, and integrating code clusters; and

5. Drawing conclusions.

First, the interviews were transcribed, read, and re-read by the authors to prepare for joint analysis. Second, the data were reduced according to thematic and theoretical coding in what Miles and Huberman describe as 'attributing a class of phenomena to a segment of text' $(1994,57)$. The coding of digitalisation initiatives was attributed to text content describing acts, activities, meaning, participation, relationships and/or referrals to context (Campbell et al. 2013). The coding was primarily led by one researcher and then discussed within the research team. This initial coding identified groups of initiatives first within each case, and later across cases. The initiatives identified were labelled increased automation, new business models, practises for problem detection and solving, enhanced communication, and developing an organisation for digitalisation.

Third, the codes were clustered based on the analytical framework, ordering and categorising the codes (i.e. the initiatives) as: exploitative and/or explorative (March 1991; Zhang, Linderman, and Schroeder 2012); affecting process, organisation, and/or business domain (Parviainen et al. 2017); whether the QM function has the mandate to lead the response to the challenge or whether the QM function is a follower and dependent on other organisational constellations; and the value creation spheres (Grönroos 2008, 2011). Coding was done according to the scheme in Appendix II.

Fourth, the condensed and reduced data was integrated with conceptual and theoretical underpinnings to further understand and draw conclusions from the data. The abductive process then allowed these analytical steps to be iterated back and forth, from consequence to antecedent (Patton 2015), between empirical data and theory in an effort to create an in-depth understanding of this phenomenon. Fifth, conclusions were drawn and discussed within the research team using a combination of tactics (Miles and Huberman 1994).

\section{Findings}

First, digitalisation initiatives involving QM were identified and categorised. Empirically, it was discovered that QM played very different roles in these initiatives. These roles ranged from taking the lead in digitalisation initiatives to taking on a pure follower role. This analysis incorporates the distinction between current, ongoing adaptive digital initiatives (exploitation) and new, developmental ways to work with digital initiatives (exploration). Secondly, key 
Table 2. Digitalisation initiatives related to QM work.

\begin{tabular}{|c|c|c|c|}
\hline \multirow[b]{2}{*}{ Digitalisation initiatives } & \multicolumn{2}{|c|}{ Types of initiatives } & \multirow[b]{2}{*}{ Leadership orientation } \\
\hline & Exploitative & Explorative & \\
\hline Enhanced communication & $\begin{array}{l}\text { Digital planning boards**, P } \\
\text { Skype**, P Team space } \\
\text { solutions**, P Digital post-it } \\
\text { notes**, P Global, internal online } \\
\text { communication*, P }\end{array}$ & $\begin{array}{l}\text { Digital pulse boards are complicated to } \\
\text { update and manage*, P Visualisation of } \\
\text { internal operations**, P Collaboration } \\
\text { despite geographical distance**, P }\end{array}$ & $\begin{array}{l}\text { Dominated by QM } \\
\text { practitioners as leaders }\end{array}$ \\
\hline $\begin{array}{l}\text { Practices for problem detection } \\
\text { and solving }\end{array}$ & $\begin{array}{l}\text { Root cause analysis in real time**, } \mathrm{P} \\
\text { Digital logs of warranty repairs**, } \\
\text { P Digital logs of product use*, P }\end{array}$ & $\begin{array}{l}\text { New capabilities for data analysis*, P Quality } \\
\text { assurance of solutions**, P Software for } \\
\text { real-time monitoring*, P/O Enabling new } \\
\text { ways to control adherence to legal } \\
\text { requirements*, B Quality errors are rapidly } \\
\text { discussed and spread through social } \\
\text { media**, O/B }\end{array}$ & $\begin{array}{l}\text { Mixed role by QM } \\
\text { practitioners - leaders } \\
\text { and followers }\end{array}$ \\
\hline $\begin{array}{l}\text { Developing an organisation for } \\
\text { digitalisation }\end{array}$ & & $\begin{array}{l}\text { Bureaucratic decision-making connected to } \\
\text { digital pulse boards*, O Making the IT } \\
\text { function more focussed on customer } \\
\text { value*, O Focussing on cross-functional } \\
\text { collaboration with IT*, O Organisational } \\
\text { structure is not updated despite new } \\
\text { investments*, O IT leads to less ownership } \\
\text { of process management*, P Making the IT } \\
\text { function more focussed on customer } \\
\text { value*, O }\end{array}$ & $\begin{array}{l}\text { QM practitioners only } \\
\text { as followers }\end{array}$ \\
\hline New business models & $\begin{array}{l}\text { Enabling new service offerings*, } 0 \\
\text { Services based on apps, }{ }^{*}, \mathrm{~B} \\
\text { Enabling new service offerings } \\
\text { (Volvo app), }{ }^{*} \text { B }\end{array}$ & $\begin{array}{l}\text { Excluding customer groups*, } 0 \text { New business } \\
\text { models, new offerings*, O/B }\end{array}$ & $\begin{array}{l}\text { QM practitioners only } \\
\text { as followers }\end{array}$ \\
\hline Increased automation & $\begin{array}{l}\text { Highly automated production lines*, } \\
\text { P Automated process to file } \\
\text { service requests*, O Digitalised } \\
\text { health care insurance*, } 0 \\
\text { Reducing customers' paper use*, } \\
\text { O Robots automating the handling } \\
\text { of service requests*, } 0\end{array}$ & & $\begin{array}{l}\text { QM practitioners only } \\
\text { as followers }\end{array}$ \\
\hline
\end{tabular}

Labels as follows: P: process level; O: organisation level; B: business model level; *: QM as follower; **: QM as leader.

characteristics of QM practitioners' roles in terms of their focus on different spheres of the value creation process were identified.

\section{Digitalisation initiatives}

Interviewees reported on several initiatives that originate from, contain, or are expected to result in digitalisation. The different initiatives vary from large-scale investments such as automation of complete production lines to initiatives with a narrower scope such as moving from physical to digital project meetings. In total, five groups of digitalisation initiatives were identified: enhanced communication, increased automation, practices for problem detection and solving, new business models, and developing an organisation for digitalisation (see Table 2). These groups were ordered in terms of QM's influence (denoted in table as leadership orientation), ranging from $Q M$ practitioners as leaders to $Q M$ practitioners as followers.

First, several initiatives pertain to digital solutions for enhanced (internal) communication such as digital planning boards and/or digital team collaboration tools. Second, increased automation can be exemplified as the automation of a variety of processes, ranging from production processes in a factory to automated service request handling related to health insurance. Third, initiatives related to practices for problem detection and solving deal with traditional tools and practices, such as root cause analysis being performed in a digital environment, that have possibilities for real-time monitoring of product performance. Fourth, new business models refer to the development of new service offerings, such as digital applications through which customers can change settings for products they use, and organisational changes resulting from these new offerings. For example, one of the cases showed that certain insurance issues can be handled in an automated way, eliminating the need for manual labour. Fifth, developing an organisation for digitalisation entails various organisational adaptions in response to digitalisation initiatives. Related to traditional QM practices, this can be exemplified by the need to have IT expertise involved in process management work as process maps become digital and interactive.

The results indicate that QM is more leader-oriented in digitalisation initiatives focussed on problem solving and communication tools that support everyday QM practices. Overall, the results show that when $\mathrm{QM}$ is more reliant on the expertise of other functions, such as IT, or when the processes are already developed, such as in automation initiatives, QM takes on a more follower-oriented role. The various roles QM plays are presented in further detail below.

With respect to 'enhanced communication' initiatives, there is a balance between more exploitative and more explorative QM practices. The results show that QM practitioners assume active roles both in adapting existing technologies and in developing new digital initiatives. Developing and improving communication tools in order to 
increase internal collaboration are key QM practices. However, these initiatives are not necessarily perceived as improving the QM work:

Sometimes, the IT function seems to think that we use whiteboards and post-it notes because we haven't yet realised that computers exist, but we do it for a specific reason: you should be able to physically touch and move them [...] and there is a flexibility if you want to change something on the board. [...] There we have the flipside of digitalization, that they [the IT function] do not understand our way of working and instead it becomes hidden in a phone or computer. [IP13]

Assuming leading roles within familiar communication practices and techniques that lie close to traditional QM practices appears to be natural. The complexity of managing new digital solutions, including in a global context, appears to be challenging where $\mathrm{QM}$ assumes more of a follower role.

In 'increased automation' initiatives, the interviewees described QM as performing only exploitative practices. The element of automation infers the use of previously developed and integrated technology in the initiatives, with QM thus assuming only a follower role. Automation, as described by the interviewees, entails taking an existing practice or process and transferring it into a digital environment without changing the content:

With the increasing automation we also get more possibilities to measure stoppages [in the production line], so that we can detect issues in real time. That is good. Compared to logging all stoppage causes and measuring losses manually, we instead get more support from our measurement system. [IP13]

Initiatives concerning 'problem detection and solving' are close to the core of QM practices. The results show that these initiatives are rather focussed on QM work based on technical systems for better data analysis. Practices are internally focussed on real-time monitoring of root cause analysis, warranty repairs, and product usage. The featured initiatives reveal a fairly equal balance between improving existing systems and developing new systems. QM is prone to adopting a leader role concerning these initiatives, either where there is a strong direct relationship to traditional QM practices or where there is the potential to utilise new sources of data in a traditional QM context. An example of the latter is when errors and countermeasures are disseminated and discussed on social media. This is a challenge for a manufacturer, but for the QM professionals it is sometimes perceived as a crucial source of data and a possibility on which to base improvements:

\footnotetext{
A big change is the sheer amount of data available [...], and we become very transparent - if anything happens to our products, the whole world will know, for better or worse. Those are new things we need to manage. [...] If someone has a bad experience and has received bad service, there is a snowball effect. Those are new information channels for quality feedback. [IP4]
}

Thus, the changes in the nature of, and channels for, quality feedback provide challenges, such as lack of control over what and where quality information is spread, as well as opportunities for more direct interaction with customers.
Regarding 'new business models' initiatives, QM practices relate to both improving service offerings for existing customers and developing service offerings for new customers, hence the balance between more exploitative and explorative QM practices. Digitalisation brings about new potential business models that differ in terms of value proposition from existing ones, often focussing on the service aspects of the offering and posing new challenges for all functions including QM practices:

We have to think about business in a completely different way [...] What is it that we should actually offer [our customers]? [...] A piece of metal is fairly straightforward - you measure it and conclude that the quality is good. [...] With a [digital] service, you are starting to throw capabilities and soft aspects into the mix. [IP24]

New business model initiatives and the related digital technology could be described as being fairly distant from traditional QM practices. The results indicate that these kinds of initiatives extend the practice range of $\mathrm{QM}$, which, in turn, could explain why QM takes on a predominant follower role.

'Developing an organisation for digitalisation' initiatives only contain explorative QM practices, with QM practitioners merely assuming follower roles. The results reveal a number of structural challenges affecting QM practices. All interviewees provided examples related to their organisation's focus on the interaction with the IT function and changed decision-making processes that are perceived to be more complicated than when the decisions were made within the QM function. The interdependence on other organisational functions, such as IT, are described as constraints for QM efforts and challenges for organisational development:

We [the organisation] are our own biggest barrier and constraint.

I don't think we speak the same language at all when it comes to digitalization. [IP11]

The results indicate a need for more collaboration with other functions within organisations in order to make digitalisation initiatives work.

\section{Digitalisation initiatives in different spheres}

Based on the previous categorisation, this section presents the digitalisation initiatives in relation to the provider, interaction, and customer spheres of value creation (Grönroos 2011). The results show that QM-related digitalisation initiatives are ongoing in all three spheres at three different levels: business, organisation and process. There is a tendency to focus more on the internal provider's role in the value creation process (see Figure 2). This is also in line with the previous results showing that $\mathrm{QM}$ takes on a leader role in 'enhanced communication' and 'problem detection and solving'. These initiatives are predominantly focussed on developing internal provider processes. Thus, the majority of the initiatives are about improving existing QM processes.

The patterns in Figure 2 above suggest that much of QM's work with digitalisation is concentrated on the internal provider sphere with a focus on the process level, but not so much on the organisation and business levels. The initiatives identified in the interaction sphere mostly contain examples 


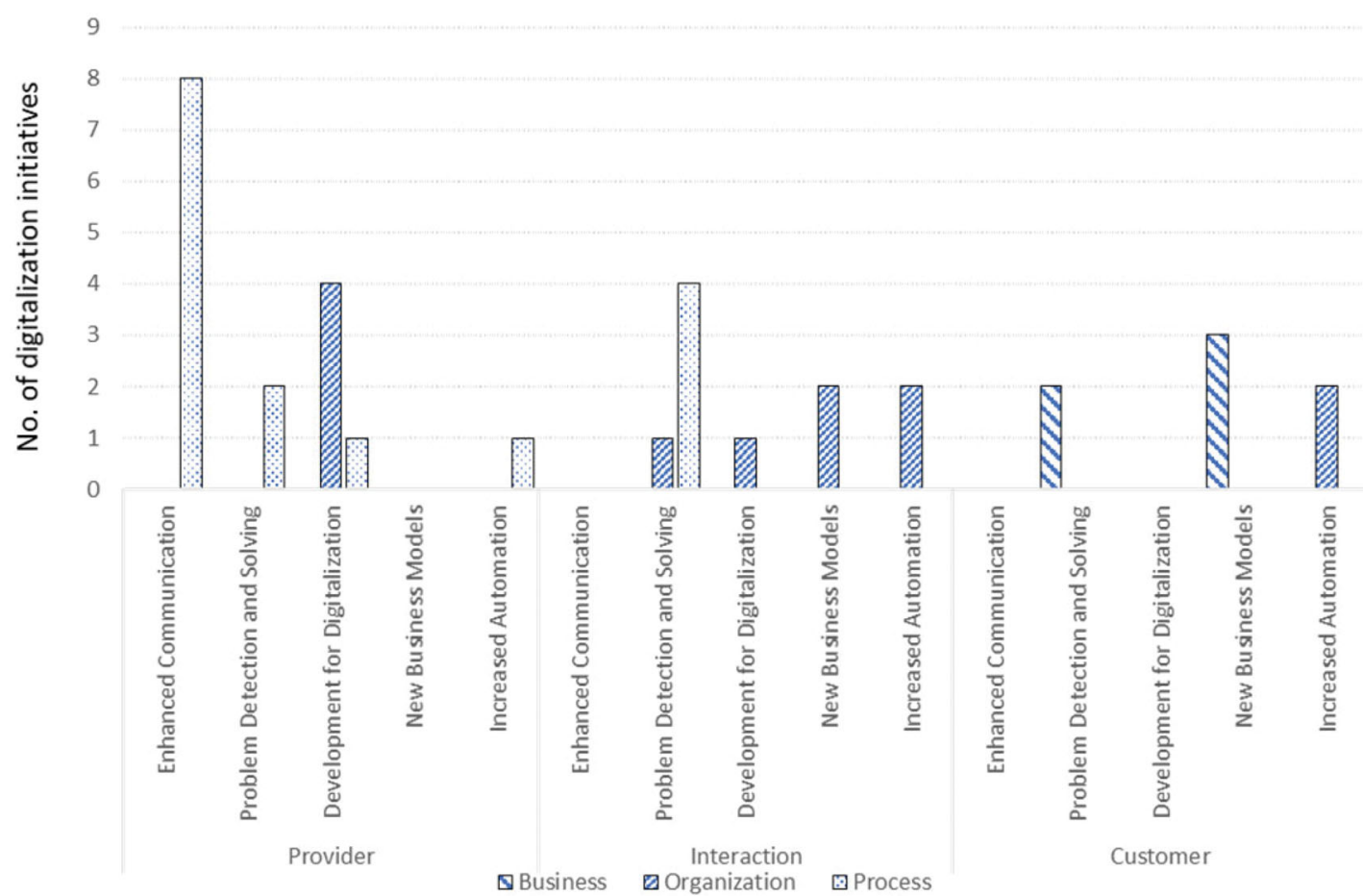

Figure 2. Digitalisation initiatives in QM with respect to the different value creation spheres (provider, interaction and customer) and levels (process, organisation and business).

at the business level, whereas the few initiatives at an organisational level are found in the customer sphere. In addition, QM has a follower role in the digitalisation initiatives that move towards the interaction and customer spheres, and it appears to struggle with its role in relation to these initiatives. When moving from the process level of digitalisation initiatives, where QM can take on a leading role, to the organisation level, several new stakeholders need to be considered. Therefore, the predominant focus in the provider sphere is on explorative 'how' questions.

Furthermore, existing initiatives in the interaction and customer spheres indicate that $\mathrm{QM}$ has a role in digitalisation, but it is limited to being participatory in nature. Looking across the whole range of initiatives, they are rather balanced in addressing and affecting the process and organisation domain levels, but few initiatives address the business domain level. Overall, there are few examples where the interviewees saw themselves as leaders of the initiatives, other than initiatives that are closely related to traditional QM tasks, such as visualising operations (e.g. process maps) and dealing with reported errors.

Digitalisation initiatives in the provider sphere are centred on the idea of making internal processes work more efficiently or supporting activities focussing on the interaction and customer spheres. Within the provider sphere, many of the digitalisation initiatives focus on developing 'enhanced communication' and 'problem detection and solving'. While the former relates to facilitating collaboration within the organisation, the latter also links the customer to the organisation through the interaction sphere. Further, the question of how to organise for digitalisation is represented well in the provider sphere. This indicates that QM works internally with different initiatives, trying to determine how they should work with other functions within the organisation. Many of these initiatives pertain to the relationship between the IT department and QM.

In the interaction sphere, digitalisation initiatives play an important role in value creation, as the interaction sphere is where the organisation has the opportunity to assist or provide resources for the customer. Digitalisation, thus, can potentially allow for many different new initiatives in this sphere. In this study, one example is 'problem detection and solving' at the process level where QM works with developing real-time monitoring systems for product use and warranty repairs. Another example is how QM takes part, as a follower, in digitalisation initiatives where the organisation develops new business models and invests in more automation.

In the customer sphere, the application of new digital solutions may present opportunities for new and hopefully more value-creating ways for customers to use resources. The role of QM in this sphere is limited to being a follower of initiatives such as 'problem detection and solving', 'new business models', and 'increased automation'. There are relatively few initiatives in this sphere, indicating that QM has a rather minor role. An obvious reason for this is that these initiatives are carried out at the business level, where roles and value chains are changing. At the business level, other actors within the organisation have leadership, such as the product development function.

In summary, four main commonalities cut across the exploitative and explorative nature of QM value creation initiatives. First, digitalisation initiatives mainly affect $\mathrm{QM}$ 's value creation within the provider sphere, and thus usually concern QM initiatives with an internal focus (i.e. initiatives with practices that support efficiency). This mainly internal focus leads 
Table 3. QM role categorisation in digitalised QM practices.

\begin{tabular}{|c|c|c|c|}
\hline & Internal focus & Integrated focus & External focus \\
\hline Exploitative roles & $\begin{array}{l}\text { Exploitative-internal role } \\
\text { - Adapting and conforming to } \\
\text { existing digital initiatives within } \\
\text { the provider sphere }\end{array}$ & $\begin{array}{l}\text { Exploitative-integrative role } \\
\text { - Maintaining and/or improving } \\
\text { digital initiatives that bridge } \\
\text { provider and customer spheres }\end{array}$ & $\begin{array}{l}\text { Exploitative-external role } \\
\text { - Improving digitalised quality in } \\
\text { already developed customer- } \\
\text { situated goods and services }\end{array}$ \\
\hline Explorative roles & $\begin{array}{l}\text { Explorative-internal role } \\
\text { - Planning and designing with } \\
\text { internal stakeholders to develop } \\
\text { new internal digital processes } \\
\text { that increase customer value }\end{array}$ & $\begin{array}{l}\text { Explorative-integrative role } \\
\text { - Management of value-in-use in } \\
\text { the digital interaction between } \\
\text { provider and customer }\end{array}$ & $\begin{array}{l}\text { Explorative-external role } \\
\text { - Developing processes to better } \\
\text { understand customer use and } \\
\text { value perception in digital } \\
\text { initiatives }\end{array}$ \\
\hline
\end{tabular}

to the second commonality in that digitalisation initiatives do not seem to be aimed at changing or increasing customer interaction or supporting value creation in the customer sphere. A third commonality is leadership and how QM professionals perceive themselves more as followers than leaders in digitalisation initiatives. The only group of QM initiatives where QM professionals assume a leadership role lies within the traditional core practices of initiatives relating to detecting and solving problems. This leads to the fourth and final commonality, where it becomes apparent that the most proficient role of QM professionals in digitalisation initiatives is that of the internally focussed problem detector and solver.

\section{Characterising QM roles in digitalisation initiatives}

In order for QM to harness the potential of digitalisation in QM practices, six roles are suggested: three exploitative roles and three explorative roles (see Table 3 ). These roles aim to address the challenges and limitations identified in mapping existing digitalisation initiatives in the studied firms. In the following sections, these roles will be discussed in relation to the corresponding challenges identified for QM in general, and for QM practitioners in particular.

\section{Exploitative roles}

The first role illustrates the empirical findings that point to the centrality of exploiting digitalised solutions for internal efficiency. This is mainly directed towards various forms of internal work methods such as how to use digital tools to communicate across space (both nationally and internationally) and improving the analysis of the large amounts of collected data. This provides a challenge in terms of adapting and conforming to digitalisation already present in the organisation. We denote this role for QM as an exploitativeinternal role for QM practitioners who are involved chiefly in caring for already existing initiatives. The next role is categorised as an exploitative-integrative role for QM practitioners which is to connect new digitalised solutions that enable movement from a human-to-human to a human-to-digital interface, for instance new service offerings or organisational forms that make fewer phone calls possible (maintaining or improving quality). The exploitative-external role for QM practitioners is related to contributing to better value in the customer sphere for already implemented digitalised solutions. For instance, QM supports the function of robots implemented to handle customer requests. All three exploitative roles specify roles related to digitalised technology that has already been implemented.

\section{Explorative roles}

The most common explorative role is that of finding collaborative partners within the organisation. This search for partners is characterised by a great deal of organisational misalignment, or structures that are not aligned with digitalised work. Many future digitalised solutions for improving internal work will require collaboration between functions. In this respect, the explorative-internal role for QM practitioners includes planning, designing, and reviewing with internal stakeholders to provide solutions that create better opportunities for the provider to offer value for the customer.

The second explorative role of $\mathrm{QM}$, which connects the provider with the customer, is the explorative-integrative QM practitioner role. This role focuses on continuous management of value-in-use and opens up opportunities for continuous value adding and interactions with the customer. The third explorative role is that of the explorative-external QM practitioner role. This role draws attention to the challenges of the emerging power structures, or the increased customer power in the customer sphere through vehicles such as social media. It also needs to contend with how to create customer value through the utilisation of the information provided by digital customer offerings such as mobile apps and 'smart' machines.

In reconciling the ambidextrous nature of both exploitative and explorative initiatives (Birkinshaw and Gibson 2004), particular challenges may be anticipated concerning the structure and organisation of the proposed QM roles. According to Zhang, Linderman, and Schroeder (2014), quality exploration contributes more to overall quality performance in organisations with high levels of competitive pressure and short product life cycles. It could thus be assumed that the performance environment is never stable, which implies a need for combined, simultaneous approaches (O'Reilly and Tushman 2013).

\section{Discussion}

\section{Characteristics of $\mathrm{QM}$ roles}

One of the key features of digitalisation is the potential to change and transform processes, organisations, and ecosystems (cf. Legner et al. 2017; Parviainen et al. 2017). When changes are significant, it also means that roles and relationships change both within and between organisations. In this 
section, the ways in which the QM role is affected are elaborated upon, and new interdependencies for QM as a consequence of digitisation are examined.

At the process level of digitalisation, QM leads initiatives that involve traditional QM practices for problem detection and solving and enhanced communication (Dean and Bowen 1994). Even though QM has a leading role in these digitalisation initiatives, they are highly dependent on the IT function as an internal supporter. In one example from the studied cases, an interviewee is mocking the administrative procedures for changing the layout of new digital pulse boards for their meetings. The relatively large focus on internal activities is pointed out in previous studies, indicating that QM's role tends to be operative rather than strategic, and internally oriented rather than customer oriented (Elg et al. 2011).

A key characteristic of QM's role at this level is the relatively high degree of freedom to develop new digital solutions to support their own work. Thus, there seems to be a match between the type of everyday work that QM is doing and the digital solutions that help them do their work better. Although some of these initiatives seem to provide QM with new ways to work with the support of digitalised solutions (e.g. new forms of communication), the tendency is that they achieve digitisation rather than digitalisation (changing from analogue to digital forms for e.g. digital pulse boards and digital post-it notes) (Henriette, Feki, and Boughzala 2016; Parviainen et al. 2017; Tilson, Lyytinen, and Sørensen 2010).

The organisational and business levels are more strategic, requiring a large amount of coordination between different business units. As the findings show, QM has a follower role in most initiatives at this level. At the organisational level, it becomes apparent that many initiatives are forming, and that QM competes with other functions to find its own role. One explanation for the increasing interdependence at the organisational and business levels is that digital technology increasingly integrates products, services, and processes, thereby changing the way that the concept of quality is perceived. Traditionally, organisations have had QM functions dealing with poor product quality. When the locus of control changes from QM practitioners to technology integration, new roles emerge.

\section{QM and the changed landscape of value creation}

It is evident that digitalisation initiatives have the potential to impact firms at various levels (Legner et al. 2017; Parviainen et al. 2017). In addition to digitalisation affecting firms both internally and externally (Dewa, van der Merwe, and Matope 2018; Henriette, Feki, and Boughzala 2016; Rothmann and Koch 2014), the boundaries between external and internal operations are increasingly blurred due to the connected nature of many digitalised products, services, and tools. In terms of QM, an example of when these blurred boundaries become apparent is with practices for problem detection and solving, which is a traditional stronghold of QM.

Firms that deliver their offering through digital interfaces such as websites, smart products, and mobile applications have the capability to collect data regarding customers' use of the product and/or service continuously and in real time. Thus, the digitalising of the offering facilitates value creation in the customer sphere by improving accessibility and availability, while at the same time enhancing QM's value facilitation processes in the provider sphere due to the available real-time data regarding current quality status and use. This ability to swiftly detect, diagnose, and solve quality issues with the aid of digitalisation lies within the reach of QM's improvement processes. It is therefore surprising to find that the studied QM practitioners have not yet seised this opportunity, seemingly regarding it as an explorative future activity.

For digitalisation initiatives related to enhanced communication, QM does not appear to take advantage of the blurring of boundaries between the provider, interaction, and customer value spheres by using new digital communication channels and platforms as inputs in their QM work. The focus is instead on digitally supported internal communication enhancements located in the provider sphere. In general, this study shows how the QM practitioner's role in digitalisation is primarily focussed on internal efficiency enhancements of existing processes and practices (i.e. digitisation). Hence, the potential for QM to cut across an organisation, as well as its value creation processes (Ponsignon, Kleinhans, and Bressolles 2019), is not fully exploited by bridging QM activities in the provider sphere with relevant activities occurring in the interaction and customer value spheres (more in line with digitalisation). Thus, QM remains internally focussed, even though it has long been argued that there is a strong customer focus at its core (Dean and Bowen 1994).

As digitalisation drives changes to existing work roles and the development of new ones (Parviainen et al. 2017; Henriette, Feki, and Boughzala 2016), developing roles that can balance QM's expertise in internally focussed quality improvements with external processes that incorporate customers' experiences and feedback will be key to moving QM beyond a supporting function located at the process-domain level. Thus, this paper proposes six roles that can help the firms' QM functions to take advantage of their core competencies, while developing new ones to aid in delivering high quality products and services in a digitalised world.

\section{Managerial implications}

This paper proposes a framework that does not view digitalisation initiatives solely based on the prerequisites needed in terms of the required technology or skills, or the expected effects on processes, organisation, or business (Parviainen et al. 2017). Rather, the framework adds to this a more outcomerelated perspective focussed on what is needed for management to exploit the potential in digitalisation and how to enable digitalisation of QM practices so that they support both exploitative and explorative outcomes. Further, the impacts of digitalisation are positioned in relation to where the impact occurs in the value creation process (Grönroos 2011). By doing so, the paper integrates several theoretical concepts that can aid in understanding how digitalisation affects QM practices and how these, in turn, can support firms' value creation. 


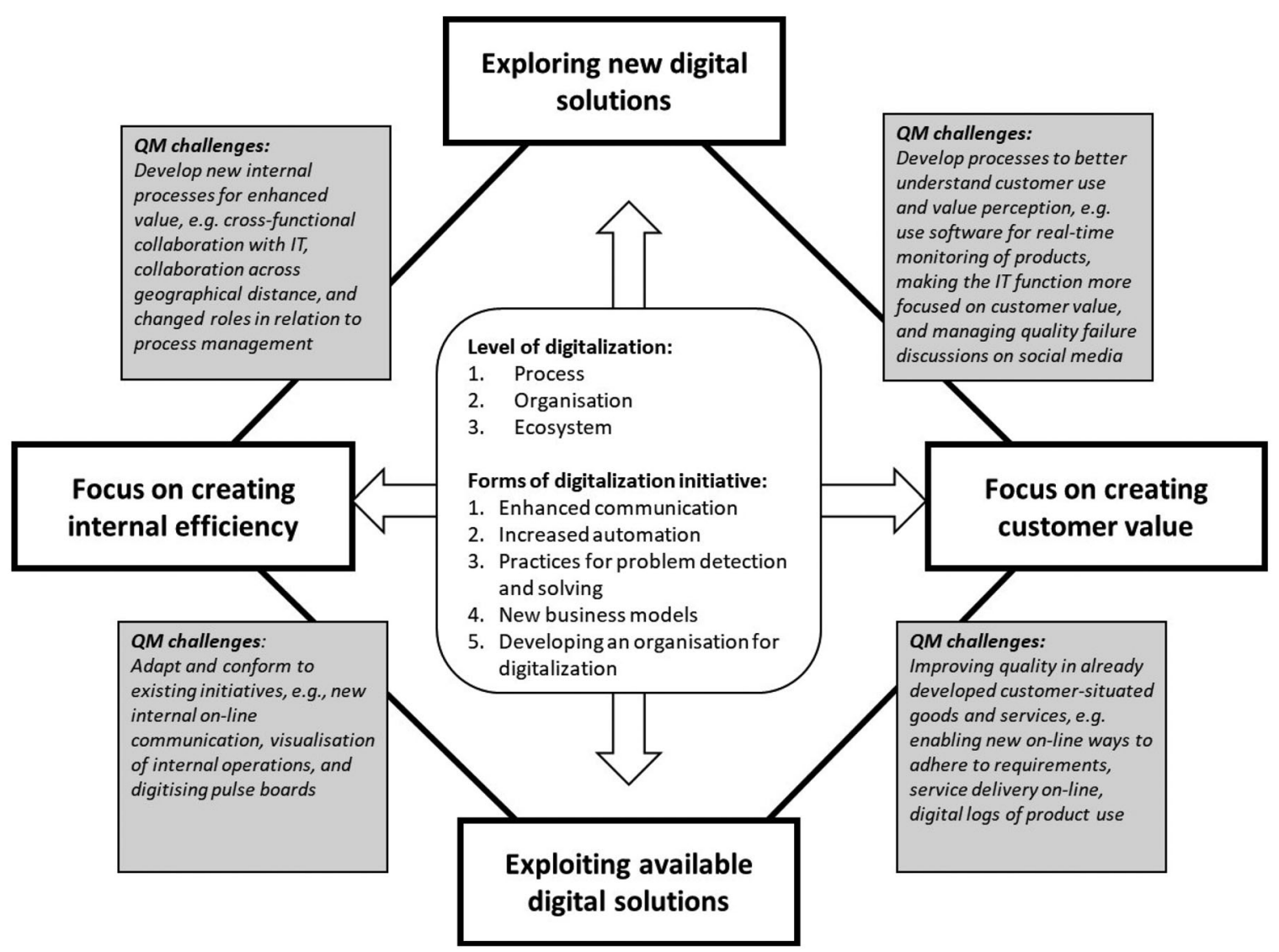

Figure 3. Summary of potential changes and challenges for Quality Management practitioners.

The digitalisation initiatives reported by the respondents predominantly affect $\mathrm{QM}$ the practices within the provider sphere (Grönroos 2011). In contrast to a presupposed impact of digitalisation on the increased centrality of customer involvement in value creation and co-creation (Zangiacomi et al. 2017; Parviainen et al. 2017; Snowdon et al. 2015), this study points to a lack of such an impact. Hence, a continued application of the value creation perspective (Grönroos 2011) on the impact of digitalisation is needed.

From a practical perspective, the study contributes to an understanding of the actual practices of QM (Sousa and Voss 2002) and the way organisational roles need to change in order to exploit the potential benefits of digitalisation (Parviainen et al. 2017; Henriette, Feki, and Boughzala 2016). Moreover, the study adds to the work of Ponsignon, Kleinhans, and Bressolles (2019) and the proposed competences needed for QM to contribute to organisations' digitalisation journeys by providing empirical examples of these anticipated changes and challenges in QM practitioners' work practices. A summary of these potential changes and challenges is provided in Figure 3.

In order to facilitate and enhance success of digitalisation initiatives and to develop necessary QM practices, this study identifies three key management imperatives: First, higher level management commitment is crucial to secure long-term outcomes. Responsibility for digitalisation initiatives should therefore not be relegated to middle or lower management levels. Any digitalisation initiative project should, as a whole or in parts supporting other initiatives, be elevated into being a senior level management priority and responsibility. Second, the findings in this study entail that the customer must be emphasised as a key driver in any digitalisation perspective. Efforts in involving customers to a higher degree and to develop QM practices that better recognise customer needs in every stage of any digitalisation initiative should be given priority. Third, it is crucial to integrate necessary IT-functions in a much more customer-oriented and business focussed way. IT-functions in support of digitalisation initiatives should be tightly connected and co-aligned with digitalisation initiative project management from an early stage. This also entails competence development for IT-functions to increase the understanding of customer needs and customer processes. Overall, for an organisation facing digitalisation, the proposed QM roles can guide an assessment of available competences and roles, as well as competence development needed in order to provide better customer value in digital initiatives.

\section{Limitations}

The focus of this study has been on the QM practitioners and their specific practices. As QM is on the agenda for staff other than QM practitioners, further studies could apply the framework proposed in this paper to other groups of practitioners who work with QM but are not part of a dedicated QM function. It is also possible to expand the study to 
include organisations outside a Swedish context, adding a variety of management and digitalisation practices.

\section{Disclosure statement}

No potential conflict of interest was reported by the author(s).

\section{Funding}

This work has been conducted as a part of HELIX Competence Centre funded by Vinnova, under Grant [2016-00418].

\section{Notes on contributors}

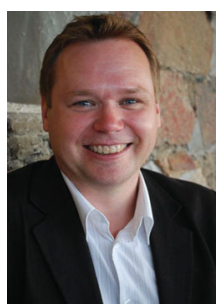

Mattias Elg is a Professor of Quality Technology and Management, Linköping University, Sweden. He is also centre director at HELIX Competence Centre, Linköping University. This Centre focuses on sustainable development in organisations by developing knowledge about how good working conditions can be combined with efficiency and innovation. Mattias research is concerned with conditions and models to manage quality and service development in organisations in both the private and public sectors. His research interests include customer co-creation, organisational change and performance measurement.

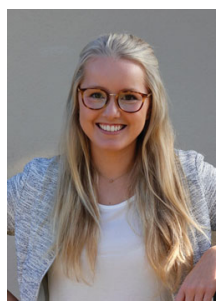

Andrea Birch-Jensen is a doctoral student at the division Service Management and Logistics in the department of Technology Management and Economics at Chalmers University of Technology, Sweden. Her research focuses on the prerequisites and capabilities needed for organisations to make use of different types of customer feedback for quality improvements, as well as the evolving role of quality management in a time of digitalisation and servitization.

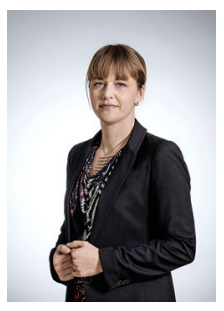

Ida Gremyr is a Professor in Quality Management at the division Service Management and Logistics, department of Technology Management and Economics at Chalmers University of Technology, Sweden. She also holds a position as a Guest Professor at Linköping University, Sweden. Gremyr's research interests focus on quality management, service quality, service development, and service innovation. She also acts as the programme director for a master's programme in Quality and Operations Management, which aligns well with her research interest in current and future roles of quality practitioners.

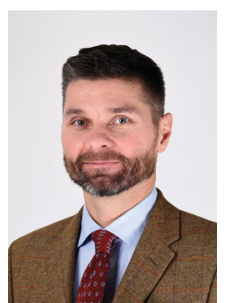

Jason Martin is a Senior Lecturer at the Division of Logistics and Quality Management in the Department of Management and Engineering (IEI) at Linköping University in Sweden. His research is mainly focussed on the application of competence theory for understanding and facilitating both adaption and development in organisations. His research interests include learning processes, organisational change and quality management. Jason Martin has a background as a commissioned officer in the Swedish armed forces and also has many years of experience from managerial and leader roles in both public and private organisations.

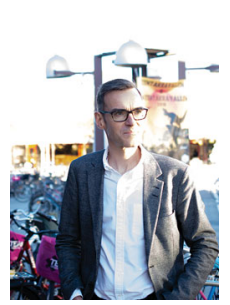

Ulf Melin is a Professor at of Information Systems, at the Department of Management and Engineering, Linköping University in Sweden. His research interests include management of digital government projects, digital service development processes, stakeholder involvement and participation, and recently also robotisation of administrative processes and open government data. Ulf leads several research initiatives on digitalisation in the public and private sector, and combine conceptual development with relevant research topics in organisational and societal levels.

\section{ORCID}

Jason Martin (D) http://orcid.org/0000-0002-5702-4885

\section{References}

Agrifoglio, R., C. Cannavale, E. Laurenza, and C. Metallo. 2017. "How Emerging Digital Technologies Affect Operations Management through Co-Creation. Empirical Evidence from the Maritime Industry." Production Planning \& Control 28 (16): 1298-1306. doi:10.1080/ 09537287.2017.1375150.

Alič, M.. 2018. "Integration of the ISO 9001 QMS with the Company's IT Business System." Total Quality Management \& Business Excellence. 29 (9-10): 1143-1160. doi:10.1080/14783363.2018.1487216.

Alvesson, M., and K. Sköldberg. 2017. Reflexive Methodology: New Vistas for Qualitative Research. London: SAGE Publications Ltd.

Arksey, H., and P. Knight. 1999. Interviewing for Social Scientists: An Introductory Resource with Examples. London: SAGE Publications Ltd.

Backström, T., A. Fundin, and P. E. Johansson. 2017. Innovative Quality Improvements in Operations: Introducing Emergent Quality Management. Springer.

Benner, M. J., and M. L. Tushman. 2003. "Exploitation, Exploration, and Process Management: The Productivity Dilemma Revisited." Academy of Management Review 28 (2): 238-256. doi:10.2307/30040711.

Berlak, J., S. Hafner, and V. G. Kuppelwieser. 2020. "Digitalization's Impacts on Productivity: A Model-Based Approach and Evaluation in Germany's Building Construction Industry." Production Planning \& Control doi:10.1080/09537287.2020.1740815.

Billon, M., F. Lera-Lopez, and R. Marco. 2010. "Differences in Digitalization Levels: A Multivariate Analysis Studying the Global Digital Divide." Review of World Economics 146 (1): 39-73. doi:10.1007/ s10290-009-0045-y.

Birkinshaw, J., and C. Gibson. 2004. "Building Ambidexterity into an Organisation." MIT Sloan Management Review 45 (4): 47-55.

Brennen, J. S., and D. Kreiss. 2016. "Digitalization." In The International Encyclopedia of Communication Theory and Philosophy, edited by K.B. Jensen, R.T. Craig, J.D. Pooley, and E.W. Rothenbuhler, 556-566. Chichester: John Wiley \& Sons Inc.

Brynjolfsson, E., and A. McAfee. 2014. The Second Machine Age. New York: WW Norton \& Company.

Campbell, J. L., C. Quincy, J. Osserman, and O. K. Pedersen. 2013. "Coding in-Depth Semistructured Interviews: Problems of Unitization and Intercoder Reliability and Agreement." Sociological Methods \& Research 42 (3): 294-320. doi:10.1177/0049124113500475.

Carlsson, C. 2018. "Decision Analytics Mobilized with Digital Coaching." Intelligent Systems in Accounting, Finance and Management 25 (1): 3-17. doi:10.1002/isaf.1421.

Christiansson, P., K. Svidt, and B. Sørensen. 2009. "Future Integrated Design Environments." Journal of Information Technology in Construction (ITcon) 14: 445-460.

Cocca, P., F. Marciano, D. Rossi, and M. Alberti. 2018. "Business Software Offer for Industry 4.0: The SAP Case." IFAC-PapersOnLine, 16th IFAC 
Symposium on Information Control Problems in Manufacturing INCOM 2018, 51, 1200-1205. doi:10.1016/j.ifacol.2018.08.427.

Dean, J. W., and D. E. Jr., Bowen. 1994. "Management Theory and Total Quality: Improving Research and Practice through Theory Development." Academy of Management Review 19 (3): 392-418. doi: 10.5465/amr.1994.9412271803.

Dewa, M. T., A. F. van der Merwe, and S. Matope. 2018. "Digitalization of Shop-Floor Operations in the South African Tool, Die, and MouldMaking Industry." South African Journal of Industrial Engineering 29 (2): 153-170. doi:10.7166/29-2-1899.

Duncan, R. B. 1976. "The Ambidextrous Organisation: Designing Dual Structures for Innovation." In The Management of Organisational Design, edited by R. Kilman and L. Pondy, 167-188. New York: North Holland.

Eisenhardt, K. 1989. "Building Theories from Case Study Research." Academy of Management Review 14 (4): 532-550. doi:10.5465/amr. 1989.4308385.

Elg, M., I. Gremyr, A. Hellström, and L. Witell. 2011. "The Role of Quality Managers in Contemporary Organisations." Total Quality Management \& Business Excellence 22 (8): 795-806. doi:10.1080/14783363.2011. 593899.

Esposito De Falco, S., A. Renzi, B. B. Orlando, and N. Cucari. 2017. "Open Collaborative Innovation and Digital Platforms." Production Planning \& Control 28 (16): 1344-1353. doi:10.1080/09537287.2017.1375143.

Evangelista, R., P. Guerrieri, and V. Meliciani. 2014. "The Economic Impact of Digital Technologies in Europe." Economics of Innovation and New Technology 23 (8): 802-824. doi:10.1080/10438599.2014.918438.

Ferrari, E., M. Gamberi, F. Pilati, and A. Regattieri. 2018. "Motion Analysis System for the Digitalization and Assessment of Manual Manufacturing and Assembly Processes." IFAC-PapersOnLine, 16th IFAC Symposium on Information Control Problems in Manufacturing INCOM 2018, 51: 411-416. doi:10.1016/j.ifacol.2018.08.329.

Ford, M. 2015. The Rise of the Robots: Technology and the Threat of Mass Unemployment. London: Oneworld Publications.

Gastaldi, L., F. P. Appio, M. Corso, and A. Pistorio. 2018. "Managing the Exploration-Exploitation Paradox in Healthcare: Three Complementary Paths to Leverage on the Digital Transformation." Business Process Management Journal 24 (5): 1200-1234. doi:10.1108/BPMJ-04-20170092.

Ghobakhloo, M. 2018. "The Future of Manufacturing Industry: A Strategic Roadmap toward Industry 4.0." Journal of Manufacturing Technology Management 29 (6): 910-936. doi:10.1108/JMTM-02-2018-0057.

Goffnett, S. P. 2020. "Leadership, Goal Acceptance, and QMS Conformance Readiness: Exploring the Mediating Effects of Audit Team Cohesion." Total Quality Management \& Business Excellence 31 (1-2): 43-67. doi:10.1080/14783363.2017.1412255.

Gölzer, P., and A. Fritzsche. 2017. "Data-Driven Operations Management Organisational Implications of the Digital Transformation in Industrial Practice." Production Planning \& Control 28 (16): 1332-1343. doi:10. 1080/09537287.2017.1375148.

Grönroos, C. 2008. "Service Logic Revisited: Who Creates Value? and Who Co-Creates?" European Business Review 20 (4): 298-314. doi:10. 1108/09555340810886585.

Grönroos, C. 2011. "Value Co-Creation in Service Logic: A Critical Analysis." Marketing Theory 11 (3): 279-301. doi:10.1177/147059311 1408177.

Grover, V., and P. Ramanlal. 2004. "Digital Economics and the E-Business Dilemma." Business Horizons 47 (4): 71-80. doi:10.1016/S00076813(04)00050-3.

Henriette, E., M. Feki, and I. Boughzala. 2016. "Digital Transformation Challenges." MCIS 2016 Proceedings 33. http://aisel.aisnet.org/ mcis2016/33.

Hoerl, R. W. 2001. "Six Sigma Black Belts: What Do They Need to Know?" Journal of Quality Technology 33 (4): 391-406. doi:10.1080/00224065. 2001.11980094.

Kohli, R., and S. Johnson. 2011. "Digital Transformation in Latecomer Industries: $\mathrm{CIO}$ and CEO Leadership Lessons from Encana Oil \& Gas (USA) Inc." MIS Quarterly Executive 10 (4): 141-156.

Legner, Christine, Torsten Eymann, Thomas Hess, Christian Matt, Tilo Böhmann, Paul Drews, Alexander Mädche, Nils Urbach, and Frederik
Ahlemann. 2017. "Digitalization: Opportunity and Challenge for the Business and Information Systems Engineering Community." Business \& Information Systems Engineering 59 (4): 301-308. doi:10.1007/ s12599-017-0484-2.

Lindgren, L.,. C. Østergaard Madsen, S. Hofmann, and U. Melin. 2019. "Close Encounters of the Digital Kind: A Research Agenda for the Digitalization of Public Services." Government Information Quarterly 36 (3): 427-436. doi:10.1016/j.giq.2019.03.002.

March, J. G. 1991. "Exploration and Exploitation in Organizational Learning." Organization Science 2 (1): 71-87. doi:10.1287/orsc.2.1.71.

Martinez, F. 2019. "Process Excellence the Key for Digitalization." Business Process Management Journal 25 (7): 1716-1733. doi:10.1108/BPMJ-082018-0237.

Miles, M. B., and A. M. Huberman. 1994. Qualitative Data Analysis: An Expanded Sourcebook. London: SAGE Publications Ltd.

O'Reilly, Charles A., and Michael L. Tushman. 2013. "Organisational Ambidexterity: Past, Present and Future." Academy of Management Perspectives 27 (4): 324-338. doi:10.5465/amp.2013.0025.

Orlikowski, W. J., and S. C. lacono. 2000. "The Truth Is Not out There: An Enacted View of the "Digital Economy." In Understanding the Digital Economy. Data, Tools and Research, edited by E. Brynjolfsson and B. Kahin, 352-380. Cambridge: MIT Press.

Parviainen, P., M. Tihinen, J. Kääriäinen, and S. Teppola. 2017. "Tackling the Digitalization Challenge: How to Benefit from Digitalization in Practice." International Journal of Information Systems and Project Management 5 (1): 63-77.

Patton, M. Q. 2015. Qualitative Research \& Evaluation Methods. London: SAGE Publications Ltd.

Ponsignon, F., S. Kleinhans, and G. Bressolles. 2019. "The Contribution of Quality Management to an Organisation's Digital Transformation: A Qualitative Study." Total Quality Management \& Business Excellence 30 (sup. 1): S17-S34. doi:10.1080/14783363.2019.1665770.

Ramaswamy, V., and K. Ozcan. 2018. "What is Co-Creation? An Interactional Creation Framework and Its Implications for Value Creation." Journal of Business Research 84: 196-205. doi:10.1016/j. jbusres.2017.11.027.

Ramírez, R. 1999. "Value Co-Production: Intellectual Origins and Implications for Practice and Research." Strategic Management Journal 20 (1): 49-65. doi:10.1002/(SICl)1097-0266(199901)20:1<49::AIDSMJ20 > 3.0.CO;2-2.

Roldán Bravo, M. I., F. J. Lloréns Montes, and A. Ruiz Moreno. 2017. "Open Innovation and Quality Management: The Moderating Role of Interorganisational IT Infrastructure and Complementary Learning Styles." Production Planning \& Control 28 (9): 744-757. doi:10.1080/ 09537287.2017.1306895.

Rothmann, W., and J. Koch. 2014. "Creativity in Strategic Lock-Ins: The Newspaper Industry and the Digital Revolution." Technological Forecasting and Social Change 83: 66-83. doi:10.1016/j.techfore.2013. 03.005.

Schiavone, F., and S. Sprenger. 2017. "Operations Management and Digital Technologies." Production Planning \& Control 28 (16): 1281-1283. doi:10.1080/09537287.2017.1375151.

Snowdon, A. W., C. Alessi, H. Bassi, R. T. DeForge, and K. Schnarr. 2015. "Enhancing Patient Experience through Personalization of Health Services." Healthcare Management Forum 28 (5): 182-185. doi:10.1177/ 0840470415588656

Sousa, R., and C. A. Voss. 2002. "Quality Management Re-Visited: A Reflective Review and Agenda for Future Research." Journal of Operations Management 20 (1): 91-109. doi:10.1016/S02726963(01)00088-2.

Stolterman, E., and A. C. Fors. 2004. "Information Technology and the Good Life." In Information Systems Research: Relevant Theory and Informed Practice, edited by B. Kaplan, 687-692. London: Kluwer Academic Publishers.

Tilson, D., K. Lyytinen, and C. Sørensen. 2010. "Research Commentary Digital Infrastructures: The Missing is Research Agenda." Information Systems Research 21 (4): 748-759. doi:10.1287/isre.1100.0318.

Tushman, Michael L., and Charles A. O'Reilly. 1996. "Ambidextrous Organizations: Managing Evolutionary and Revolutionary Change." California Management Review 38 (4): 8-23. doi:10.2307/41165852. 
Voss, C., N. Tsikriktsis, and M. Frohlich. 2002. "Case Research in Operations Management." International Journal of Operations \& Production Management 22 (2): 195-219. doi:10.1108/ 01443570210414329.

Yin, R. K. 2013. Case Study Research: Design and Methods. London: SAGE Publications Ltd.

Zangiacomi, A., J. Oesterle, R. Fornasiero, M. Sacco, and A. Azevedo. 2017. "The Implementation of Digital Technologies for Operations Management: A Case Study for Manufacturing Apps." Production Planning \& Control 28 (16): 1318-1331. doi:10.1080/09537287.2017.1375142.

Zangiacomi, A., E. Pessot, R. Fornasiero, M. Bertetti, and M. Sacco. 2020. "Moving towards Digitalization: A Multiple Case Study in
Manufacturing." Production Planning \& Control 31 (2-3): 143-157. doi: 10.1080/09537287.2019.1631468.

Zhang, D., K. Linderman, and R. G. Schroeder. 2012. "The Moderating Role of Contextual Factors on Quality Management Practices." Journal of Operations Management 30 (1-2): 12-23. doi:10.1016/j.jom.2011.05. 001.

Zhang, D., K. Linderman, and R. G. Schroeder. 2014. "Customizing Quality Management Practice: A Conceptual and Measurement Framework." Decision Sciences 45 (1): 81-114. doi:10.1111/deci.12059.

Zhou, J. 2013. "Digitalization and Intelligentization of Manufacturing Industry." Advances in Manufacturing 1 (1): 1-7. doi:10.1007/s40436013-0006-5.
Appendix I. Overview of interviewees

\begin{tabular}{|c|c|c|c|}
\hline Organisation & Interviewee code & Title & Category of role \\
\hline \multirow[t]{9}{*}{ Manufacturing A } & IP1 & & Decentralised/strategic \\
\hline & IP2 & & Decentralised/strategic \\
\hline & IP3 & & Decentralised/strategic \\
\hline & IP4 & & Centralised/strategic \\
\hline & IP5 & & Centralised/strategic \\
\hline & IP6 & & Decentralised/strategic \\
\hline & IP7 & & Centralised/strategic \\
\hline & IP8 & & Decentralised/strategic \\
\hline & IP9 & & Centralised/operational \\
\hline \multirow[t]{5}{*}{ Life Science Firm } & IP10 & & Centralised/operational \\
\hline & IP11 & & Decentralised/strategic \\
\hline & IP12 & & Decentralised/operational \\
\hline & IP13 & & Centralised/strategic \\
\hline & IP14 & & Decentralised/strategic \\
\hline \multirow[t]{8}{*}{ Government Body } & IP15 & & Decentralised/strategic \\
\hline & IP16 & & Centralised/operational \\
\hline & IP17 & & Centralised/strategic \\
\hline & IP18 & & Centralised/strategic \\
\hline & IP19 & & Decentralised/operational \\
\hline & IP20 & & Centralised/operational \\
\hline & IP21 & & Centralised/operational \\
\hline & IP22 & & Centralised/strategic \\
\hline \multirow[t]{11}{*}{ Manufacturing B } & IP23 & & Centralised/strategic \\
\hline & IP24 & & Centralised/strategic \\
\hline & IP25 & & Centralised/strategic \\
\hline & IP26 & & Decentralised/strategic \\
\hline & IP27 & & Centralised/operational \\
\hline & IP28 & & Centralised/operational \\
\hline & IP29 & & Decentralised/operational \\
\hline & IP30 & & Centralised/operational \\
\hline & IP31 & & Centralised/operational \\
\hline & IP32 & & Centralised/operational \\
\hline & IP33 & & Centralised/operational \\
\hline
\end{tabular}

Appendix II. Coding scheme

\begin{tabular}{|c|c|}
\hline Code clustering categories & Coding guidelines \\
\hline Exploitative & $\begin{array}{l}\text { - Identifying existing customers } \\
\text { - } \quad \text { Assessing and understanding customer } \\
\text { needs and expectations } \\
\text { - Increasing process control and reliability } \\
\text { - Intra-functional problem-solving } \\
\text { - Training on existing skills }\end{array}$ \\
\hline Explorative & $\begin{array}{l}\text { - Identifying new customers and new } \\
\text { customer needs } \\
\text { - } \quad \text { Involving customers in product development } \\
\text { - } \quad \text { Exploring new products and processes } \\
\text { - } \quad \text { Dynamic changes to the organisation } \\
\text { - } \quad \text { Cross-functional problem-solving } \\
\text { - Training on multiple and new skills }\end{array}$ \\
\hline Process level & $\begin{array}{l}\text { - Refers to digital tools in solving tasks } \\
\text { and activities }\end{array}$ \\
\hline Organisation level & $\begin{array}{l}\text { - Refers to digitalisation initiatives facilitating } \\
\text { the improvement of existing } \\
\text { customer offerings } \\
\text { - Refers to digitalisation initiatives facilitating } \\
\text { the development of new customer offerings }\end{array}$ \\
\hline Business domain level & $\begin{array}{l}\text { Refers to digitalisation initiatives facilitating } \\
\text { the improvement of existing business } \\
\text { models and value chains } \\
\text { - Refers to digitalisation initiatives facilitating } \\
\text { the development of new business models } \\
\text { and value chains }\end{array}$ \\
\hline Mandate (follower/leader) & $\begin{array}{l}\text { - Refers to QM as leading digitalisation } \\
\text { initiatives } \\
\text { - Refers to QM as following digitalisation } \\
\text { initiatives }\end{array}$ \\
\hline Provider sphere & $\begin{array}{l}\text { - Refers to digitalisation initiatives developing } \\
\text { and facilitating value in internal processes }\end{array}$ \\
\hline Interaction sphere & $\begin{array}{l}\text { - Refers to digitalisation initiatives developing } \\
\text { and facilitating value together } \\
\text { with customers }\end{array}$ \\
\hline Customer sphere & $\begin{array}{l}\text { - Refers to digitalisation initiatives in } \\
\text { gathering information on customer } \\
\text { behaviour, needs, and wishes } \\
\text { - Refers to digitalisation initiatives in } \\
\text { understanding customer value-in-use }\end{array}$ \\
\hline
\end{tabular}

